\title{
THE SIGNIFICANCE OF WAVE REFLECTION ON THE MORPHOLOGY OF INTERTIDAL MUDFLATS
}

\author{
Elizabeth Chellew ${ }^{1}$, Kate Rossington ${ }^{2}$, Ian Townend ${ }^{1,2}$, Carl Amos ${ }^{1}$ and Stephen Richardson ${ }^{2}$ \\ The influence of seawalls in modifying the equilibrium form of a shoreline has previously caused extensive debate. A \\ numerical model was used to predict the equilibrium form of muddy intertidal profiles, along a shoreline in \\ Southampton Water, UK. It was found that the profile containing a seawall had a very different profile form to the \\ undefended sites, and that this seawall profile could not be accurately represented in the model. The model was \\ extended to include wave reflection from the seawall, producing a new prediction with a much improved resemblance \\ of the observed profile. It was concluded that the likely cause of the different profile form at the site of the seawall in \\ this case, is due to incident and reflected wave interaction.
}

Keywords: equilibrium form, seawalls, wave reflection.

\section{INTRODUCTION}

The effect of wave dissipation on the morphology of intertidal areas has been the topic of extensive study for both cohesive (Lee and Mehta 1997) and non-cohesive (Dean 1991) sediments. Analytical and numerical models have been used to examine the equilibrium form of intertidal areas in response to tide and wave conditions (Fredrichs and Aubrey 1996; Roberts et al. 2000). Wave reflection from a seawall, particularly how it might modify the equilibrium form of shorelines, has caused extensive debate. The majority of the studies undertaken on seawalls have been in relation to sandy beaches (Kraus and McDougal 1996). In this study we consider how an equilibrium form on a cohesive intertidal profile is altered by wave reflection and use a numerical model to predict the likely influence of a seawall.

Cohesive intertidal environments are often found in estuaries, where more sheltered conditions are experienced than the open coast. Mudflats are able to provide a natural protection of the shoreline, by dissipating a high proportion of wave energy over the mudflat width (Dyer 1998). As a result of this wave attenuation however, forces acting on the seabed will cause a gradual weakening of the surface sediment. The turbulent motion caused by wave activity can be sufficient to cause the advection of surface particles straight into suspension (Whitehouse et al. 2000). Wave reflection causes an additional wave energy component acting on the mudflat surface, increasing the overall level of wave activity over the intertidal area.

Seawalls, described by Van Rijn (1998) as a 'vertical retaining wall', form a shore parallel structure, preventing waves and water levels from reaching the land behind. Although, often constructed to protect an eroding shoreline, seawalls do not address the erosion cause, but simply manage some of the effects, for example, shoreline retreat (Silvester 1978). Seawalls dissipate very little of the incoming wave energy, and therefore reflect a high component of the energy back into the intertidal environment. The proportion of wave energy reflected is dependent on the material and slope of the seawall and the properties of the local sediment.

\section{MODEL DESCRIPTION}

The numerical model used for this study was an intertidal profile model created and developed at HR Wallingford (Roberts et al. 2000; Rossington et al. 2009). The model predicts the equilibrium profile of a mudflat, in response to different forcing factors including tidal range, sediment concentration and wave conditions. The model is based on and described by the assumption that 'an equilibrium can exist between the shape of a mudflat and the hydrodynamic forcing, which leads to a stable mudflat morphology' (Roberts et al. 2000). The equilibrium morphology was also defined by Roberts et al. as 'the state where no net sediment transport occurs, when considered over a suitably long period'.

Using this model, Roberts et al (2000) suggested that wave action produced steeper and more concaved profile shapes. Recently, the Roberts et al model has been extended to included a more detailed and physically realistic representation of tides and waves, and the inclusion of a long-shore current (Rossington et al. 2009).

\footnotetext{
${ }^{1}$ School of Ocean and Earth Sciences and School of Civil Engineering and the Environment, University of Southampton, UK

${ }^{2}$ HR Wallingford, Howbery Park, UK
} 
There are three hydrodynamic forcing components to the model: cross-shore and long-shore currents and waves. Cross-shore currents are represented by assuming a conservation of mass only, therefore ignoring the conservation of momentum (Equation 1);

$$
\frac{\partial h}{\partial t}+\frac{\partial(u h)}{\partial x}=0
$$

where $h$ is water depth, $x$ is cross-shore distance and $u$ is the depth averaged velocity

As the water level at the seaward boundary of the model rises and falls, water is forced on and off the modelled intertidal, carrying sediment by advection. A sediment concentration is specified at the seaward boundary, and varies over a spring-neap tidal cycle, so that more sediment is available during spring tides than during neaps. Sediment is transported only by cross-shore currents in the model, described by an advection equation with erosion and deposition represented by source and sink terms (Equation 2);

$$
\frac{\partial(c h)}{\partial t}+\frac{\partial(u c h)}{\partial x}=Q_{e}-Q_{d}
$$

where c is the depth averaged sediment concentration, $Q_{e}\left(\mathrm{kgm}^{-2} \mathrm{~s}^{-1}\right)$ is the flux away from the bed by erosion and $Q_{d}$ the flux towards the bed by deposition.

The cross-shore movement of water produces a shear stress at the bed, which is proportional to velocity. Long-shore currents and waves create additional shear stress at the seabed but do not transport any sediment in this model. A feedback relationship exists between the long-shore currents and the water depth, so that if the water depth shoals due to accretion, long-shore current velocities will increase locally.

Erosion will occur when the predicted shear stress (currents and waves) is greater than the threshold shear stress for erosion (Equation 3). Deposition however, is dependent on the sediment concentration and occurs at all shear stresses (Equation 4), including times of erosion (Winterwerp 2007);

$$
\begin{aligned}
& Q_{e}=m_{e}\left(\frac{\tau_{b}}{\tau_{e}}-1\right) \\
& Q_{d}=c \cdot w_{s}
\end{aligned}
$$

where $\mathrm{m}_{\mathrm{e}}$ is the erosion rate constant $\left(\mathrm{kgm}^{-2} \mathrm{~s}^{-1}\right), \tau_{b}$ is the bed shear stress $\left(\mathrm{Nm}^{-2}\right)$, and $\tau_{e}$ is the critical bed shear stress for erosion, $c$ is the depth averaged concentration $\left(\mathrm{gl}^{-1}\right)$ and $\mathrm{w}_{\mathrm{s}}$ is the settling velocity for deposition $\left(\mathrm{ms}^{-1}\right)$.

A combined shear stress $\left(\tau_{\text {tot }}\right)$ is calculated from the cross-shore and long-shore currents $\left(\tau_{c}\right)$ and wave shear stresses $\left(\tau_{w}\right)$ (Equations 5 to 7 ).

$$
\begin{aligned}
& \tau_{\text {tot }}=\tau_{c}+\tau_{w} \\
& \tau_{c}=\rho C_{D}\left(u_{\text {cross }}{ }^{2}+u_{\text {long }}{ }^{2}\right) \\
& \tau_{w}=\frac{1}{2} \rho f_{w} U_{w}{ }^{2}
\end{aligned}
$$

where $\rho$ is the density of seawater $\left(1026 \mathrm{kgm}^{-3}\right), u_{\text {cross }}$ is the cross-shore current velocity (ms $\left.{ }^{-1}\right), u_{\text {long }}$ is the long-shore current velocity, $C_{D}$ is the drag coefficient, $f_{w}$ is the wave friction factor assuming a smooth turbulent flow (Soulsby, 1997) and $U_{w}$ is the peak orbital velocity from a wave (ms ${ }^{-1}$ ).

An initial beach profile shape is adjusted by the model according to the sediment flux between the water column and the seabed. A series of nodes are created at equal cross-shore distances, assigned input seabed elevations from the initial profile. Long-shore current and boundary water level conditions were extracted from a flow model of the area over a spring-neap cycle; the same spring-neap 
cycle was repeated for the duration of the simulation. In this study the model used 20 minute timesteps and was run for 50 years.

The model was extended to account for a reflected wave component that might be expected at a location of a seawall (Chellew, 2009). If the water level in the model was higher than the toe of the wall then a reflection of the wave would occur, given a total wave height $H_{\text {tot }}$ that was the sum of the incident $H_{i}$ and reflected $H_{r}$ waves (Equation 8).

$$
H_{t o t}=\sqrt{\left(H_{i}\right)^{2}+\left(H_{r}\right)^{2}}
$$

\section{APPLICATION}

The model was applied to investigate the impact of reflected waves from a seawall on an intertidal mudflat in Southampton Water, UK. Profiles for a length of muddy shore in Southampton Water (Figure 1), have been collected by Associate British Ports (ABPmer) annually over a period of 10 years (1996-2005). This data set was used in conjunction with field assessment, to identify changes of substrate and the presence of coastal defence structures. Seven cross-shore profiles along the eastern shore of Southampton Water were used for this study (Figure 1 and Table 1), extending from profile 21 in the south-east to profile 33 in the north-west. Six of these profiles consisted of natural shorelines, without coastal defense structures present. However, one profile was situated at a site defended by a sheet pile seawall. Over the 10 year period the profiles revealed a high degree of stability, albeit subject to some inter-annual variability in response to changing wave and tide conditions.

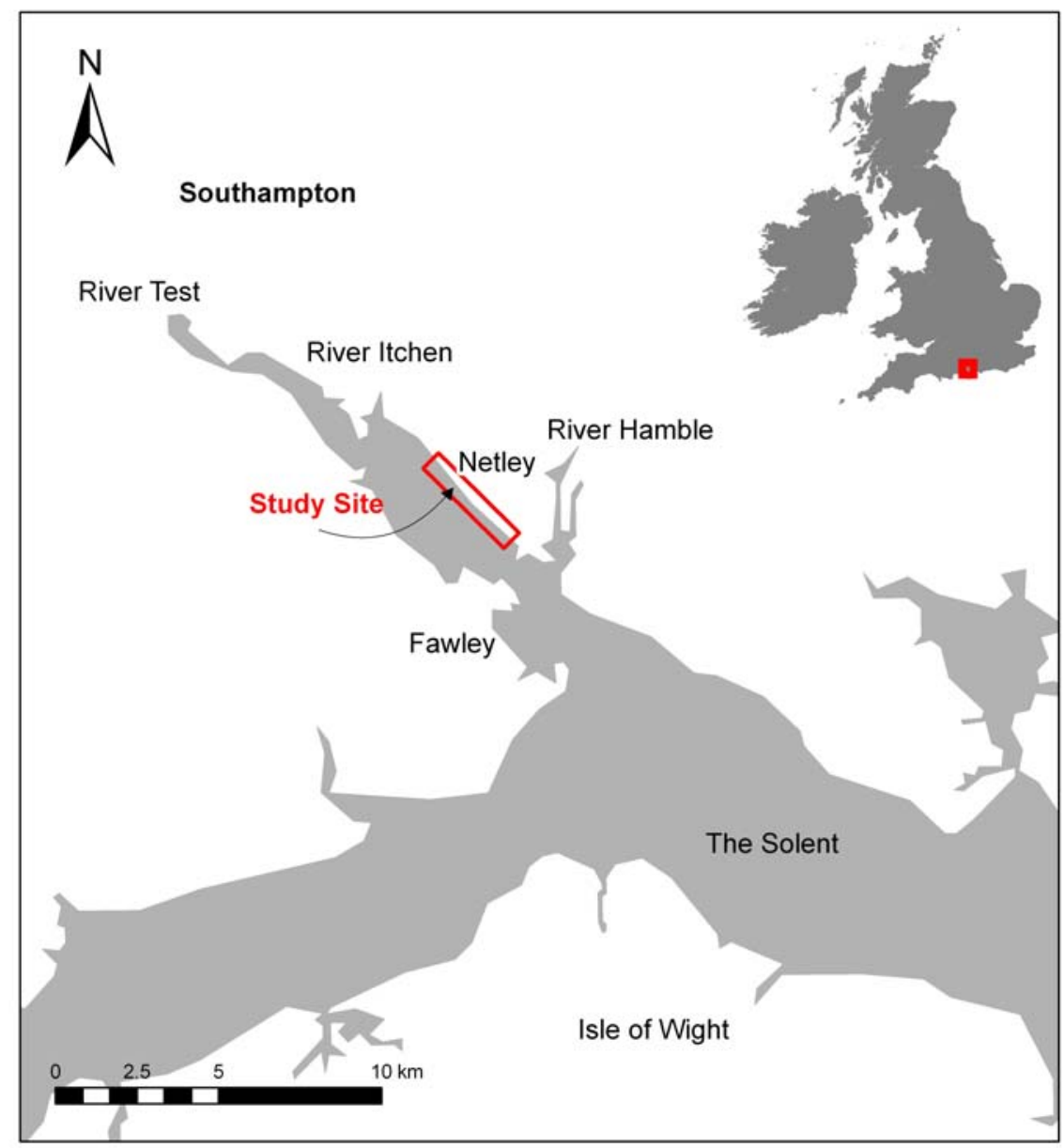

Figure 1. The locations of the study site along Netley Shore of Southampton Water, UK 


\begin{tabular}{|l|l|}
\hline \multicolumn{2}{|l|}{ Table 1. Beach and defence information at profile sites. } \\
\hline Profile 21 & Undefended Shore (River Hamble end of shoreline) \\
\hline Profile 23 & Undefended Shore \\
\hline Profile 25 & Sheet Pile Wall \\
\hline Profile 27 & Undefended Shore \\
\hline Profile 29 & Undefended Shore \\
\hline Profile 31 & Undefended Shore \\
\hline Profile 33 & Undefended Shore (River Itchen end of shoreline) \\
\hline
\end{tabular}

The numerical profile model (as described previously in Model Description) was used to represent the local conditions at the profiles. Inputs from the TELEMAC 2D hydrodynamic model were used to create the tidal input needed for a spring-neap cycle. Wave heights were calculated using measured local wind data, at 20 minutes intervals, for the duration of one year (2001) by Associate British Ports Southampton (ABP). Sediment parameters were informed by beach inspection and previous research undertaken in the local area (SCOPAC, 2004; ABPmer, 2006; ABPmer and HR Wallingford, 2007).

\section{RESULTS}

A marked difference was observed, between undefended and seawall profiles, for the data collected along a length of shoreline in Southampton Water. It was hypothesised that wave reflection, either from the steeper, shingle covered, upper portion of the beach, or from the seawall provided a possible explanation for these observed differences in profile shape. A selection of these profiles can be seen in Figure 2. Profile 25 shows the greatest difference to the other profiles observed, and coincides with the length of protected shoreline. The shingle veneer along the upper beach, was found from beach inspection but can also be seen in profiles 21, 29 and 33, where similar, steep profile gradients at $10-15 \mathrm{~m}$ cross-shore are found at the inshore end. This change in bed slope could be caused by an abrupt change in sub-straight type with distance cross-shore.

Although a significant difference in morphology was observed between the profiles, a high degree of stability was seen over time for each profile, suggesting that the intertidal area here may be close to equilibrium. This is supported by the findings of Price and Townend (2000) that the bed in Southampton Water is surprisingly stable. 


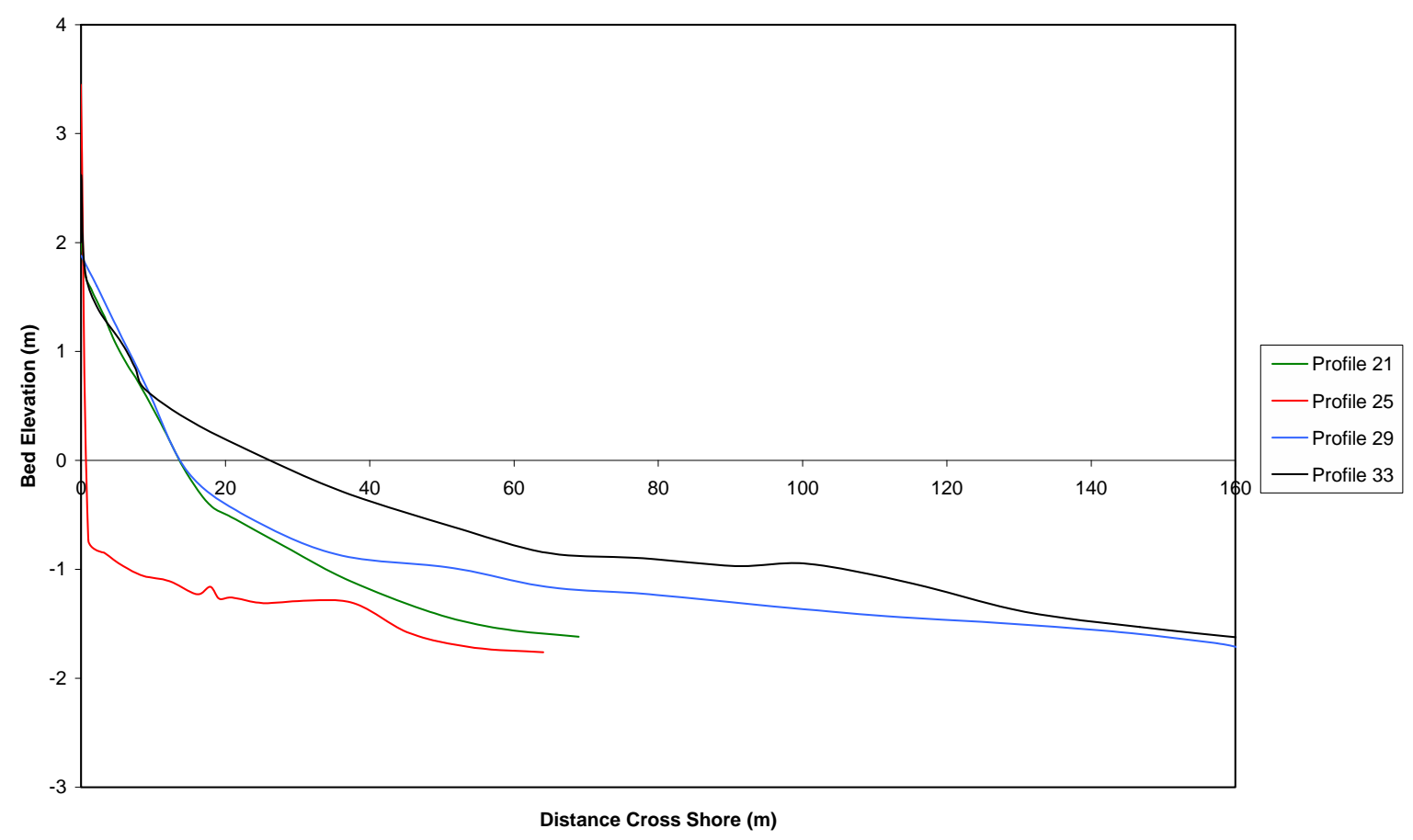

Figure 2. Field observations for a range of profile in Southampton Water for 2001.

The numerical profile model was used to identify the equilibrium form of the intertidal profiles. Some minor adjustments to the erosion threshold were required in order to calibrate the model against the six observed profiles (Table 2). Initially all the profiles were considered to be unaffected by coastal structures (seawalls) and therefore wave reflection was not included. Model predictions showed a good agreement against the measured bathymetry in the six cases with no seawall (Figures 3 and 4). The profile form became stable in the model, with little further change occurring after a run time of 30-40 years.

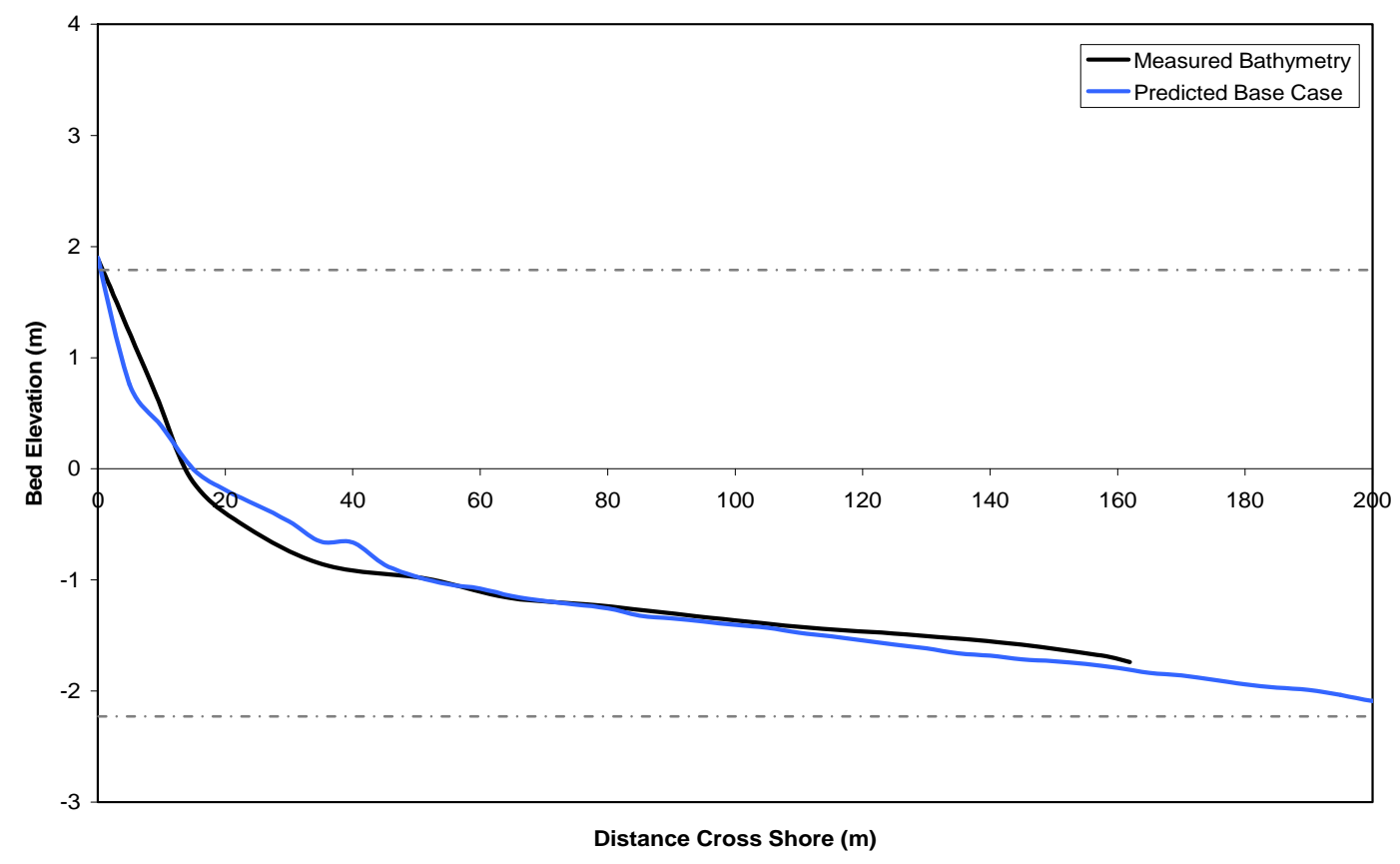

Figure 3. Comparison of profile 29 from the numerical model prediction against the measured data. 


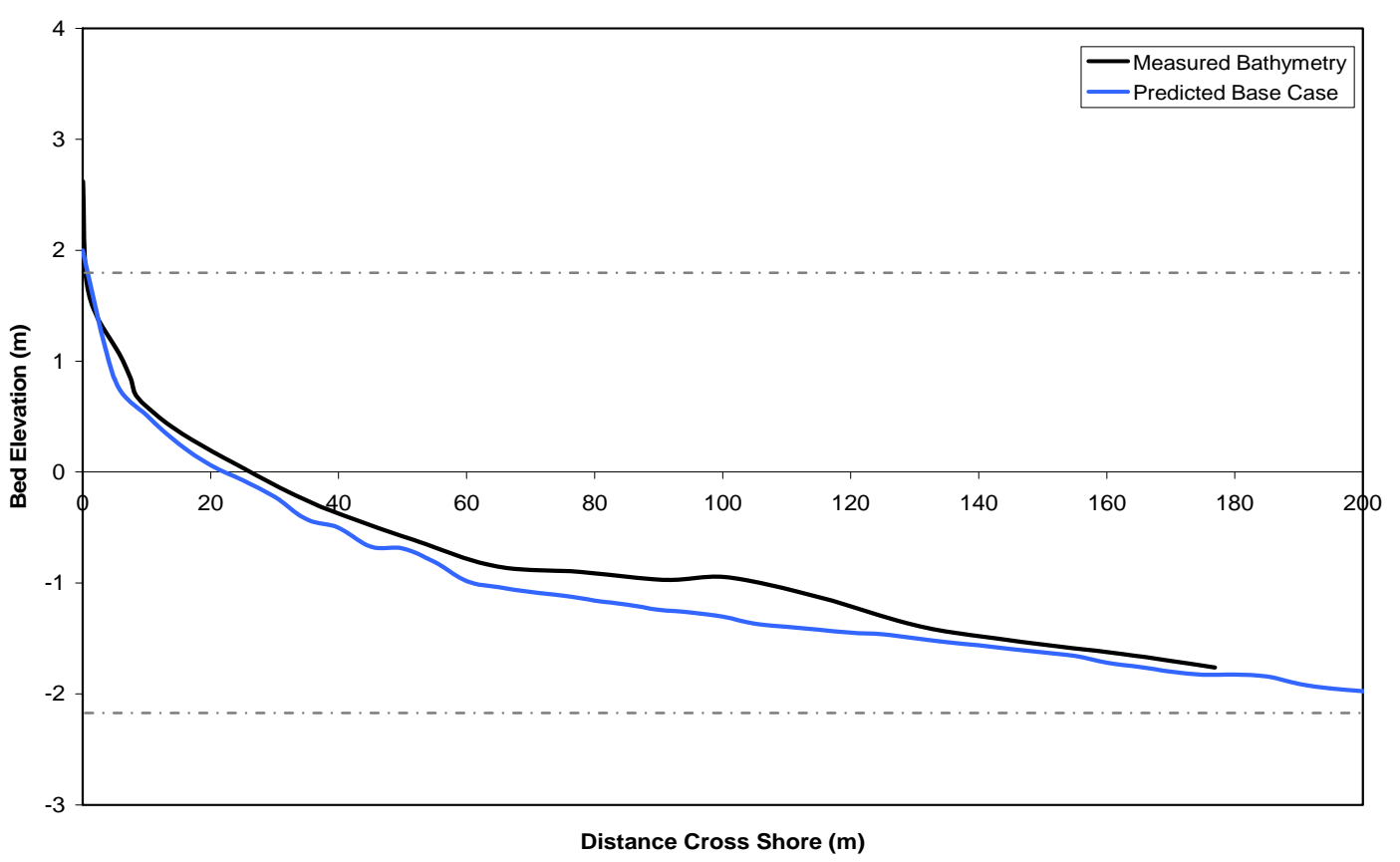

Figure 4. Comparison of profile 33 from the numerical model prediction against the measured data.

The root mean squared difference was used to quantify the difference between the model prediction and the observed profile form, this ranged from 0.08 to $0.15 \mathrm{~m}$. The ranges of sediment parameters are found in Table 2, where most are in the range considered appropriate for fine sediment. The only exception is for erosion threshold, which was slightly greater than the typical range for fine sediments (0.1-0.2 Nm $\mathrm{Nm}^{-2}$, although still within the overall range of 0.02-5.0 Nm $\mathrm{Nm}^{-2}$ (Mitchener et al. 1996). The coarser grained veneer of sediment found along the upper portion of the beach at locations along this site, might account for this.

The results obtained using the representative parameter settings for the conditions at the majority of the other sites, did not produce a similar profile form to what was observed at profile 25 . The root mean square difference for this profile was $0.31 \mathrm{~m}$, larger than found at the other profile sites (Table 2).

\begin{tabular}{|c|c|c|c|c|c|c|}
\hline \multicolumn{6}{|c|}{ Table 2. Sediment Parameters for intertidal profile used in the numerical model (not including wave reflection). } \\
\hline Profile & $\begin{array}{c}\text { Erosion } \\
\text { Threshold } \\
\left(\mathrm{Nm}^{-2}\right)\end{array}$ & $\begin{array}{c}\text { Settling Rate } \\
\left(\mathrm{ms}^{-1}\right)\end{array}$ & $\begin{array}{c}\text { Erosion Rate } \\
\text { Constant } \\
\left(\mathrm{kgm}^{-2} \mathrm{~s}^{-1}\right)\end{array}$ & $\begin{array}{c}\text { Boundary } \\
\text { Concentration } \\
\left(\mathrm{gl}^{-1}\right)\end{array}$ & $\begin{array}{c}\text { Bed } \\
\text { Roughness } \\
\text { Length (m) }\end{array}$ & $\begin{array}{c}\text { Root Mean } \\
\text { Squared } \\
\text { Difference (m) }\end{array}$ \\
\hline 21 & 0.30 & 0.0001 & 0.0008 & 0.04 & 0.0002 & 0.12 \\
23 & 0.33 & 0.0002 & 0.0008 & 0.02 & 0.0002 & 0.15 \\
27 & 0.39 & 0.0001 & 0.0008 & 0.04 & 0.0002 & 0.08 \\
29 & 0.40 & 0.0002 & 0.0008 & 0.02 & 0.0002 & 0.09 \\
31 & 0.39 & 0.0002 & 0.0008 & 0.02 & 0.0002 & 0.08 \\
33 & 0.40 & 0.0002 & 0.0008 & 0.02 & 0.0002 & 0.15 \\
\hline 25 & 0.30 & 0.0001 & 0.0008 & 0.04 & 0.0002 & 0.31 \\
\hline
\end{tabular}

Predictions were re-produced for profile 25 containing the seawall using the updated model described above. Model predictions with and without the seawall are shown in Figure 5. A marked improvement was obtained for the profile in relation to the observed data, for the case including wave reflection, giving a root mean squared difference of $0.06 \mathrm{~m}$. The difference between the profile predictions with and without wave reflection is shown in the cross-shore area between 0 and $60 \mathrm{~m}$. Wave reflection is predicted to cause a lowering of the seabed close to the seawall, as a result of the additional reflected wave component present. The lower bed levels are also seen in the observed data 
for profile 25. Cross-shore node intervals are spaced at intervals of $5 \mathrm{~m}$, clarifying why the seabed drop at the seawall is not as steep as in the observed profiles.

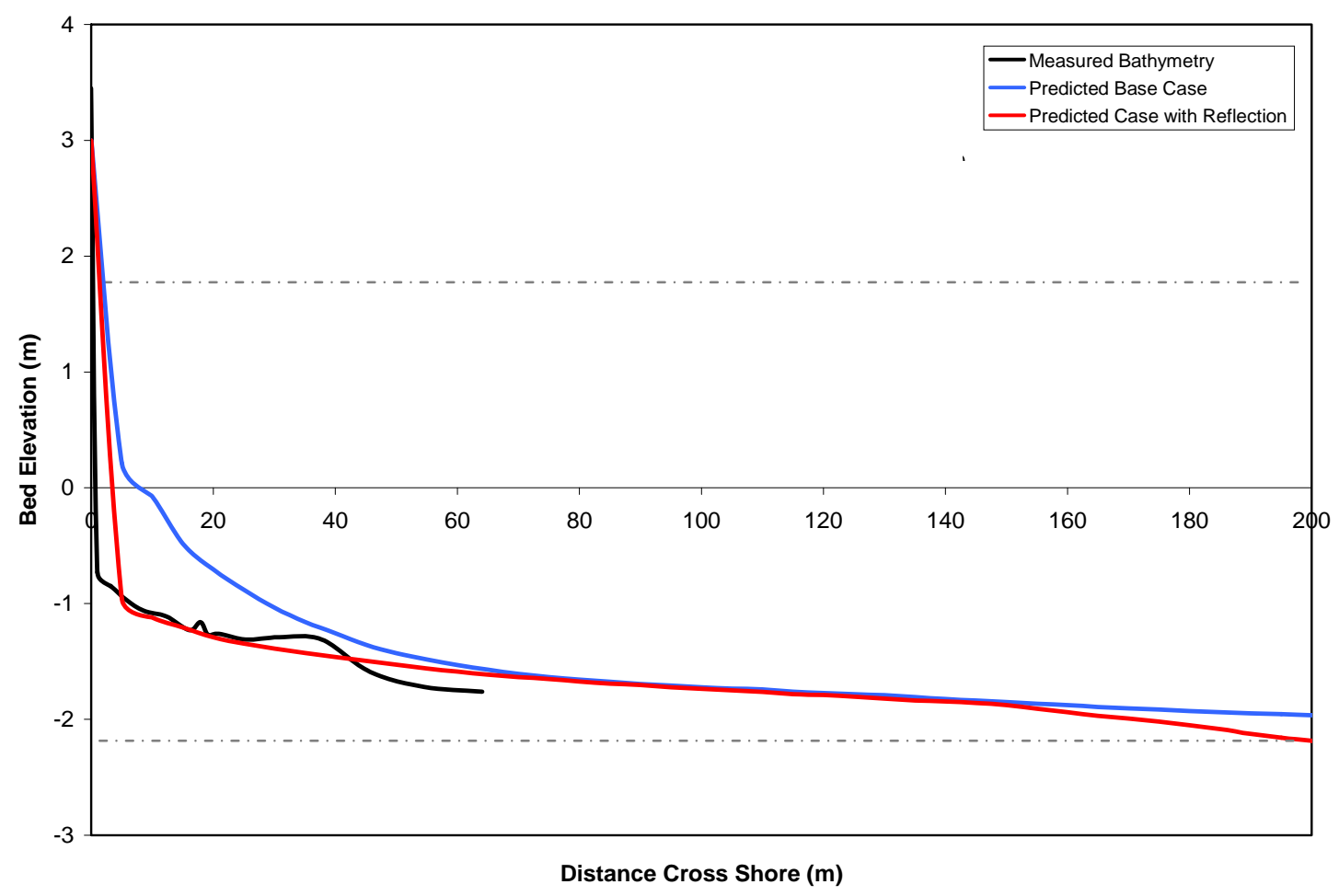

Figure 5. Comparison of predicted base case (without reflection) and predicted case (with reflection) to measured profile (Profile 25).

In February 2001 there was a severe storm event captured in the wind data, with associated wave heights reaching $1.1 \mathrm{~m}$. This was shown to have a significant effect on the profile, causing erosion at the shoreward end (Figure 6). Despite the erosion being limited to the initial 30m cross-shore, a substantial amount of beach lowering occurred. However, the model results suggest a good recovery at the site, returning to its original form by the end of the year. Intermediate time steps through the year, shows an accretion of sediment gradually re-building the profile and causing the raising of bed level at the shoreward end. 


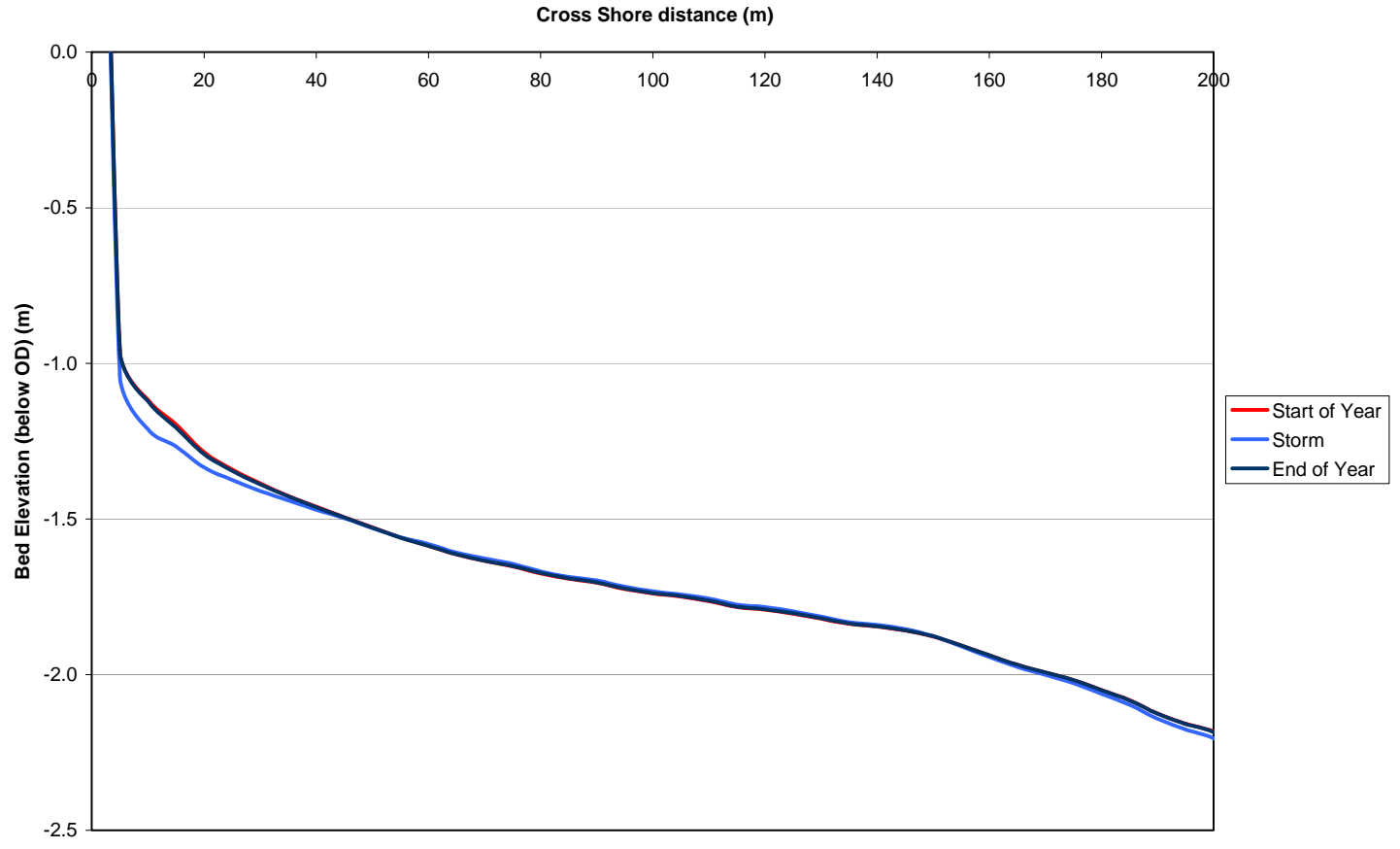

Figure 6. Profile changes as a result of a severe storm in a single year (profile 25).

\section{DISCUSSION}

The intertidal profile model was used to produce realistic muddy intertidal profiles for the six undefended shore sites, found in Southampton Water. The error values (root mean squared difference) have shown only a small difference between the calibrated model and the field observations, with values varying from $8-15 \mathrm{~cm}$ (Table 2). This level of error indicates a good overall representation of the study site by the intertidal model. The small discrepancies that do occur between the model prediction and the observed data could be due to some of the assumptions made in the model. For example; wave breaking processes are not included and sediment parameters are assumed constant across the profile in the model.

Profile 25 has a very different observed form to the six undefended profiles along the same length of shoreline (Figure 2). The only physical difference between the profile site for 25 is the presence of a sheet pile seawall. The observed profile shows an almost vertical bed slope, with a bed elevation reducing from $+3 \mathrm{~m}$ to $-0.7 \mathrm{~m}$ OD within a metre. After this drawdown the profile is not a smooth bed slope extending offshore, as was found in most of the undefended sites. Instead, an area of raised seabed is found 35-40m offshore. This deposition of sediment at this point might represent the patterns of varying scour, similar to that predicted for standing wave conditions. This deposition feature could suggest the presence of a nodal point, with an anti-node forming at the inshore end.

When modelled in a similar way to the other undefended profiles, a large discrepancy was found between the predicted profile and the observed data for profile 25 (Figure 5). The error value for this profile was $31 \mathrm{~cm}$. The undefended profile sites are positioned on either side of the sheet pile wall, which suggest that the physical properties and sediment characteristics are relatively stable alongshore (Table 2). The difference in profile shape would therefore seem to be caused by the seawall.

The much greater level of erosion observed at the toe of the seawall, than was predicted in the model, without wave reflection, was investigated. The position of the seawall is below the mean water level, where for a large portion of the tidal cycle, the water is able to affect the local transport of sediment.

The extended model was applied to the profile, using a reflected wave component from the seawall, acting on the seabed, where much greater levels of erosion were predicted at the shoreward end. This produced a remarkably similar form to that found in the observed data (Figure 5). The bed gradient at the shoreward end is not quite as steep as observed due to the $5 \mathrm{~m}$ cross-shore spacing of model nodes. A reduction in the spacing of nodes, increasing the inshore resolution would be expected to make the slope even steeper, as found in the observed data. The inclusion of wave reflection from 
the seawall in the model, creates an extra source of energy, producing a greater force on the seabed and causes increased local erosion. The average difference between the observed and modelled profiles was dramatically reduced from $31 \mathrm{~cm}$ to $6 \mathrm{~cm}$, with the inclusion of wave reflection in the model. For this case wave reflection in the model provides an accurate and suitable explanation of the processes occurring in the profile that are not found at the other natural, undefended sites.

All the model assumptions and simplifications (e.g. wave breaking) are equally applied to each of the profiles in this study. The influence of wave reflection can therefore be considered using the relative differences between the model predictions. If this relative difference was to be ignored however, the other influential factors can still be ruled out. Wave breaking forces are greater in shallow water, than deeper water. The near-shore water depth is greater for the profile containing the seawall than for the undefended profiles. Wave breaking can therefore be excluded as a cause of the erosion found at the seawall in the model. Also, if an increase in bed shear stress had been accounted for in the near-shore, it would have produced a steeper intertidal profile, again not causing the effect found at the seawall.

The coarse sediment surface on the near-shore portion of the beach in several of the profiles, enables a steeper bed slope, compared to that of a mud profile. This steep shingle veneer could cause a partial wave reflection, due to the coarse nature of the sediment. Some test runs were undertaken using the same formula as was used for the seawall, but with a lower reflection coefficient. Reflection coefficients produced by Goda (2000) suggested that a natural beach could reflect $0.05-0.2$ of the incoming wave height and that a slope with rubble stones would reflect 0.3-0.6. The shingle slope might be expected to fall within these two categories, predicting about a 0.3 or $30 \%$ reflection. It was found that this did not represent the observed profiles for the sites being considered, using the existing model equations used for the reflection of a seawall, and some further work would be needed.

The wave data created was for 2001 containing a storm in February, producing wave heights up to $1.1 \mathrm{~m}$. The influence of this storm caused erosion to the toe of shingle upper shore (Figure 6), lowering the bed by about $10 \mathrm{~cm}$ at the point of maximum erosion. After the storm, the profile was found to slowly recover over the course of a year. By the end of the year the modelled profile resembles a very similar profile shape to that which had been produced before the storm had occurred. This suggests that although there might be increased short-term erosion from storm waves, the profile is predicted to restore its previous state of equilibrium after the storm has finished in the long-term.

\section{CONCLUSION}

There is a distinctive difference between muddy intertidal profiles with and without seawalls. Analysis from theory, observations and modelling of the different profile form in front of a seawall, leads to the conclusion that this is caused by incident and reflected wave interaction. This interaction causes an enhanced influence to the seabed and therefore increased erosion. Incorporating this in modelling tools should improve both the assessment of impacts, and the design of seawalls in particular, to take account of beach lowering and scour at the toe of the wall. It would be useful for further work, to apply the model at other locations, to find if similar results can be produced. Also, extension of the 1-D representation to consider waves approaching at oblique angles, therefore developing a 2-D wave field of the incident and reflected waves would improve the near bed representation.

\section{ACKNOWLEDGMENTS}

The authors are grateful to ABPmer and ABP Southampton for kindly making several valuable data sets available. The modelling was undertaken by Elizabeth Chellew as part her Masters studies at the University of Southampton, during a placement at HR Wallingford.

\section{REFERENCES}

ABPmer 2006. River Itchen, River Hamble, Weston, Netley and Hamble Shore. Coastal Defence Strategy for Southampton City Council, Supported by Eastleigh and Fareham Borough Councils, Phase 1: Coastal Processes Baseline Statement. R.1277.

ABPmer \& HR Wallingford. 2007. The Estuary-Guide: A website based overview of how to identify and predict morphological change within estuaries. Website prepared for the joint Defra/EA Flood and Coastal Erosion Risk Management R\&D Programme. November 2007. Available at: http://www.estuary-guide.net/.

Chellew, E.S.deM. 2009. The significance of wave reflection of the morphology of upper intertidal mudflats. MSc. Thesis, University of Southampton. 
Dean, R.G. 1991. Equilibrium Beach Profiles: Characteristics and Applications, Journal of Coastal Research, 7(1), 53-84.

Dyer, K.R. 1998. The typology of intertidal mudflats. In: Black, K.S., D.M. Paterson, \& A. Cramp (Eds.) Sedimentary Processes in the Intertidal Zone. Geological Society, London, Special Publication, 139, 11-24.

Friedrichs, C.T. \& D.G. Aubrey. 1996. Uniform bottom shear stress and equilibrium hypsometry of intertidal flats, In: Pattiaratchi (Ed.), Mixing in estuaries and coastal seas, AGU, Washington, 405429.

Goda, Y. 2000. Random Seas and design of maritime structures, (Advanced Series on Ocean Engineering - Volume 15). Singapore: World Scientific Publishing Co. Pte. Ltd.

Kraus, N.C. \& W.G. McDougal. 1996. The Effects of Seawalls on the Beach: Part I, An Updated Literature Review, Journal of Coastal Research, 12(3), 691-701.

Lee, S.-C. \& A.J. Mehta. 1997. Problems in characterizing dynamics of mud shore profiles, Journal of Hydraulic Engineering, ASCE, 123(4), 351-361.

Mitchener, H, J. 1996. Properties of dredged material. A review of available measurement techniques for determining physical properties. HR Wallingford Report TR 21.

Price, D., \& I. Townend. 2000. Hydrodynamic, Sediment Process and Morphological Modelling. In: Collins, M. \& K. Ansell. (Eds.), Solent Science - A Review. Amsterdam: Elsevier Science B.V. 5570 .

Roberts, W., P. Le Hir, \& R.J.S. Whitehouse. 2000. Investigation using simple mathematical models of the effect of tidal currents and waves on the profile shape of intertidal mudflats, Continental Shelf Research, 20(10-11), 1079-1097.

Rossington, K., R.J.S. Whitehouse, \& J. Spearman. 2009. Morphological modelling of intertidal profiles in estuaries with strong tidal currents, In: Proc. Rivers, Coastal \& Estuarine Morphodynamics, Santa Fe, Argentina, 941-946.

Silvester, R. 1978. The roll of wave reflection in coastal processes. In: Coastal Sediments'77:Fifth Symposium of the Waterway, Port, Coastal and Ocean Division of ASCE. New York: American Society of Civil Engineers, 639-654.

Soulsby, R.L. 1997. Dynamics of marine sands. A manual for practical applications. London: Thomas Telford Publishing.

Standing Conference on Problems Associated with the Coastline (SCOPAC), 2004. Southampton Water, Available from: http://www.scopac.org.uk/scopac\%20sediment\%20db/soton/index.htm.

Van Rijn, L.C. 1998. Principles of Coastal Morphology, Netherlands: Aqua Publications.

Whitehouse, R.J.S., R.L. Soulsby, W. Roberts, H. Mitchener. 2000. Dynamics of estuarine muds. A manual for practical applications. London: Thomas Telford Publishing.

Winterwerp, J.C. 2007. On the sedimentation rate of cohesive sediment. In: Maa, J.P.-Y., L.P. Sandford, D.H. Schoelhamer (Eds.) Estuarine and Coastal Fine Sediment Dynamics, Elsevier, pp 209-226. 